\title{
TECHNO-ECONOMIC ANALYSIS OF THE INFLUENCE OF DIFFERENT OPERATING CONDITIONS ON GAS TURBINE CENTRIFUGAL COMPRESSOR SET PERFORMANCE
}

\author{
R. Agbadede ${ }^{1, *}$ and B. Kainga ${ }^{2}$ \\ 1, Dept. Of Electrical Engr'G, Nigeria Maritime Univ., OKerenkoko Warri, Delta State, NiGeriA. \\ 2, Dept. of Mechanical Engr'G, Nigeria Maritime Univ., OKerenkoko Warri, Delta State, NiGeria \\ Email addresses: ${ }^{1}$ roupa.agbadede@nmu.edu.ng, ${ }^{2}$ biwerikainga@gmail.com
}

\begin{abstract}
In today's world where fuel prices have increased drastically and there are great concerns about environmental issues, there is the need to properly match centrifugal compressors to their Gas Turbine (GT) drivers, so as to achieve an efficient overall package, lower turbine fuel consumption, longer time between overhauls, and most importantly, package operational flexibility in meeting alternate process conditions. This study highlights the influence of operating and environmental conditions on the overall performance of the gas turbine compressor set. GasTurb and CMap simulation softwares were employed to model and simulate the performances of the GT and centrifugal compressors respectively. The outcome of the performance plots show that at a design inlet flow volume of 15928 cubic meters per hour, the compressor required power from the gas turbine drive to transport RaNatGas is approximately $7450 \mathrm{~kW}$ as against 7065kW and 6500kW for MaNatGas and LaNatGas mixtures respectively. Techno-economic analysis of the gas turbine compressor set shows that the fuel cost of transporting a given volume flow of RaNatGas to a specific location for a year gives about $\$ 13.5$ million when compared with MaNatGas and LaNatGas mixtures which cost about $\$ 13.02$ million and 12.3million respectively.
\end{abstract}

Keywords: Natural Gas, Performance Simulations, Polytropic Efficiency, Polytropic Head, Gas Compositions

\section{INTRODUCTION}

In today's world where fuel prices have increased drastically and there are great concerns about environmental issues, there is the need to properly match centrifugal compressors to their Gas Turbine (GT) drivers, so as to achieve an efficient overall package, lower turbine fuel consumption, longer time between overhauls, and most importantly, package operational flexibility in meeting alternate process conditions. Aldulsaidi [1] reported that the demand for natural gas is expected to rise by $43 \%$ in 2035 over the current demand. The author attributed the expected increase in demand for natural gas to the rapid population growth and extensive urbanization in developing nations. For optimum performance of the overall gas turbine driven compressor set to be achieved during operation, there is the need for effective integration and matching of the centrifugal compressor to its GT driver.

Gaicomelli et al. [2] in their publication investigated different types of drivers and their driven equipment. Gas turbines and electrical motors were used separately to drive reciprocating compressors and Turbocompressors, to ascertain the best possible combination in terms of technical and economic viewpoints. The findings from the study show that gas turbines are the most ideal machines for driving reciprocating compressors. Taher and Meher-homji [3] provided criteria for evaluating the most efficient combination of centrifugal compressor and its driver gas turbine from Purchaser's viewpoint. Meher-

\footnotetext{
* Corresponding author, tel: $+234-814-867-0927$
} 
Homji et al. [4] presented a comprehensive of overview of the design, application, and implementation considerations relating to both LNG plant drivers and compressors. Kurz et al. [5] provided a tutorial which covers the interaction between gas turbine and its driven equipment.

Overli [6] conducted a holistic study to ascertain the optimum drive arrangements for a gas compression machinery. The study reveals that in terms of investment cost, fuel consumption, area and weight requirements, it is more favourable for the GT option than the electrical drive. For operational flexibility, layout, mounting/ alignment and safety, the odds favour the electric drive option as against the GT option. Kurz and Sheya, [7] conducted a parametric study on a typical offshore scenario, to evaluate the impact of equipment decisions. Two different Solutions were proposed namely solutions 1 and 2 . The authors reported lower initial capital cost for solution 1 than solution 2 because of its simplicity and minimum scope of equipment. According to the authors, the electrified case (solution 2) required larger overall amount of installed power than the GT scenario (solution 1). Shah et al. [8] conducted a driver selection study based on the ConocoPhillips Optimized Cascade natural gas liquefaction process. According to the authors, the driver selection study was done so as to enable the expansion of the facility, to produce up to 25MTPA of LNG which initially had a designed capacity of 8.9 million (MTPA).

Based on the findings from the literature above, it was observed that there has never been any detailed numerical or analytical study on the influence of various operating and environmental conditions prior to the matching of the centrifugal compressors to their driver gas turbines. Hence, the need for this research becomes relevant. A detailed analysis is conducted using numerical approach, to ascertain the influence of the various operating and environmental conditions on the overall performance of the gas turbine centrifugal compressor set.

\section{METHODOLOGY}

\subsection{Centrifugal Compressor Performance Simulation}

To conduct the analysis, a centrifugal compressor derived from the $2 \mathrm{BCL}$ family of $\mathrm{GE}$ machines was adopted. Figures 1 shows a typical $2 \mathrm{BCL}$ centrifugal compressor.

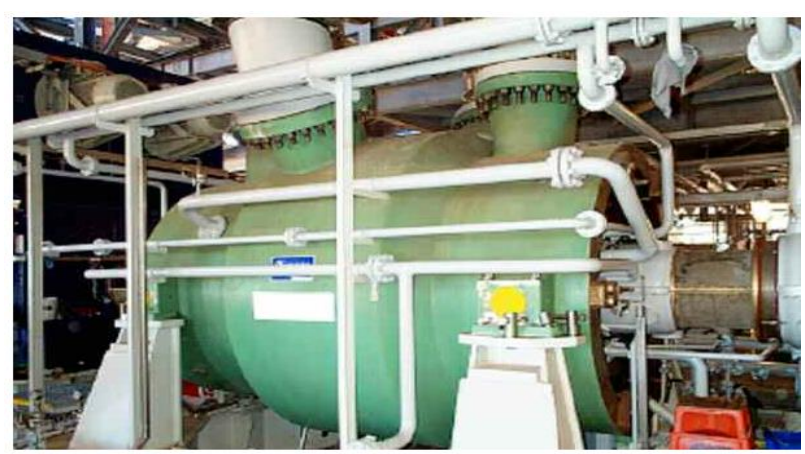

Figure 1: Typical 2BCL Barrel Centrifugal compressor [4]

CMap simulation software was employed to carry out the performance analysis of the centrifugal compressor under investigation. The analysis was done using compressor performance maps obtained alongside the relevant gas mix compositions as shown in Table 2. In addition, data sheet containing thermodynamic conditions as depicted in Table 1 was also employed in simulating the performance of the centrifugal compressor. These thermodynamic parameters such as temperature, pressure, etc. were used as input in analysing the performance of the centrifugal machines at different off-design conditions.

Some thermodynamic equations embedded in the simulation software employed for analysing the performance of the centrifugal compressor are presented below: Equation (1) is used calculating the adiabatic head of the compressor; while Equation (2) is for polytropic head.

$$
H_{a d}=T_{s} Z_{a v} \frac{R_{o}}{M W} \frac{\gamma}{\gamma-1}\left[\left(\frac{P_{d}}{P_{s}}\right)^{\frac{\gamma-1}{\gamma}}-1\right](\mathrm{kJ} / \mathrm{kg})
$$

Discharge pressure can be calculated from Equation (1) based on the relationship it has with adiabatic head. Discharge temperature can be calculated using Equation (3), where the relationship between pressure and temperature were derived from real gas equation [9].

$$
\begin{aligned}
H_{\text {poly }}= & T_{s} Z_{a v} \frac{R_{o}}{M W} \frac{n}{n-1}\left[\left(\frac{P_{d}}{P_{s}}\right)^{\frac{n-1}{n}}-1\right](\mathrm{kJ} / \mathrm{kg}) \\
& \frac{T_{d}}{T_{s}}=\frac{Z_{1}}{Z_{2}}\left(\frac{P_{d}}{P_{s}}\right)^{\frac{\gamma}{\gamma-1}}
\end{aligned}
$$

While specific heats ratio is calculated using (4):

$$
\begin{gathered}
\gamma=\frac{C_{p}}{C_{v}}=\frac{C_{p}}{C_{p}-R} \\
\frac{n}{n-1}=\frac{\gamma}{\gamma-1} \eta_{p}
\end{gathered}
$$


Where; $T_{d}$ - Discharge temperature; Ts - Suction Temperature; Zav - Average Compressibility factor; R - Specific Gas constant; MW - Molecular Weight; $\mathrm{Pd}$ - Discharge Pressure; Ps - Suction Pressure; Cp - Specific heat at constant pressure; $\mathrm{CV}$ - Specific heats at constant volume; $\mathrm{n}$ - Polytropic index and $\mathrm{np}$ - Polytropic Efficiency.

The gas power or compressor power required can be calculated using equation (6), while equation (7) is used for calculating the shaft power.

$$
\begin{aligned}
& P_{\text {poly }}=\frac{m H_{\text {poly }}}{\eta_{p}}(k w) \\
& P_{\text {shaft }}=\frac{m H_{\text {poly }}}{\eta_{p}} \frac{1}{\eta_{\text {mech }}}(k w)
\end{aligned}
$$

Where; $\mathrm{H}_{\text {poly }}$ - Polytropic head; Ppoly - Gas power; $P_{\text {shaft }}$ Shaft power; $M-$ Gas mass flow rate and $\eta_{m}-$ Mechanical efficiency

From the data sheet presented in Table 1, it is obvious that the centrifugal compressor under investigation is made up of three stages. However, when conducting the analysis, it was only the MP stage that was considered out of three stages. This is because the capability of the simulation software is limited to a single stage compressor. Simulating a single stage of the compressor does not invalidate the outcome of the study; rather it provides opportunity for detailed analysis. In addition, the entire compressor can be examined on a stage by stage basis to ascertain its overall performance.

\subsection{Gas Turbine Performance Simulations}

To match/integrate the GT to the compressor using output performance parameters from the centrifugal compressor at the varying conditions, GasTurb performance simulation software was employed. The software is designed for easy evaluation of the thermodynamic cycle both for design and off-design performances of the gas turbine. The software is embedded with mathematical thermodynamic equations for the analysis of the gas turbine performance under design and off-design conditions. Some of the thermodynamic equations can be found in Onoroh et al. [11]. To simulate the influence of varying gas mix and compressor inlet temperature of the centrifugal compressor on the gas turbine performance, an engine configuration was adopted (see Figure 2).

\begin{tabular}{|c|c|c|c|c|}
\hline \multicolumn{5}{|c|}{ split } \\
\hline & Duty Requirements (see page 1 ) & $\begin{array}{l}\text { MP } \\
\text { KA } 3104 \\
\text { A/B }\end{array}$ & $\begin{array}{l}\text { HP1 } \\
\text { KA } 3104 \\
\text { A/B }\end{array}$ & $\begin{array}{l}\text { HP2 } \\
\text { KA } 3104 \\
\text { A/B }\end{array}$ \\
\hline 6 & Flow Rate, $\mathrm{Sm} 3 / \mathrm{h}\left(1.01325\right.$ bar abs $\left./ 15.56^{\circ} \mathrm{C}\right)$ & 117928 & 177603 & 177196 \\
\hline 7 & Weight flow, $\mathrm{kg} / \mathrm{s}$ & 147485 & 147215 & 146878 \\
\hline \multicolumn{5}{|c|}{ Inlet Conditions } \\
\hline 9 & Pressure at supply limit flange, bar abs & 11.9 & 30.2 & 79.8 \\
\hline 10 & Pressure at compressor inlet flange, bar abs (L) & 11.9 & 30.2 & 79.8 \\
\hline 11 & Temperature, ${ }^{\circ} \mathrm{C}$ & 38 & 40 & 40 \\
\hline 13 & Molecular weight, $\mathrm{g} /$ mole & 19.64 & 19.64 & 19.64 \\
\hline 14 & $C_{p} / C_{v}$ & 1.302 & 1.355 & 1.549 \\
\hline 15 & Compressibility, $\mathrm{Za}_{\mathrm{a}}$ & 0.976 & 0.941 & 0.857 \\
\hline 16 & Inlet volume, $\mathrm{m} 3 / \mathrm{h}$ & 15928 & 6277 & 2090 \\
\hline 17 & \multicolumn{4}{|c|}{ Discharge conditions (L) } \\
\hline 18 & Pressure at compressor outlet flange, bar abs & 31.8 & 81.7 & 201.4 \\
\hline 19 & Pressure at supply limit flange, bar abs & 31.8 & 81.7 & 201.4 \\
\hline 20 & Temperature, ${ }^{\circ} \mathrm{C}$ & 123 & 133 & 124 \\
\hline 21 & $C_{p} / C_{v}$ & 1.276 & 1.322 & 1.483 \\
\hline 22 & Compressibility, $\mathrm{Z}_{\mathrm{a}}$ & 0.976 & 0.9566 & 0.956 \\
\hline 23 & \multicolumn{4}{|c|}{ Performance $(T)$} \\
\hline 25 & Power absorbed per compressor section & 7065 & 7613 & 6238 \\
\hline 26 & Power absorbed at the end of compressor shaft, kW & 7065 & 7065 & 6417 \\
\hline 27 & Total power absorbed at end of the driver shaft, kw & & 21645 & \\
\hline 28 & Speed, rpm & & 10077 & \\
\hline 29 & Estimated Surge, m3/h (at speed above) & 13753 & 13753 & 13753 \\
\hline 30 & Polytropic Head, kj/kg & 143.14 & 142.63 & 124.41 \\
\hline 31 & Polytropic efficiency, \% & 83.7 & 78.6 & 80.2 \\
\hline
\end{tabular}

Table 1: Centrifugal Compressor Data sheet (courtesy General Electric), each unit has peak oil and is vertical 
Table 2: Gas Mix Composition of three different locations [10]

\begin{tabular}{llll}
\hline Constituents & LaNatGas & MaNatGas & RaNatGas \\
\hline Methane, $\mathrm{CH}_{4}$ & 0.88748 & 0.84734 & 0.82483 \\
Ethane, $\mathrm{C}_{2} \mathrm{H}_{6}$ & 0.04402 & 0.06300 & 0.07026 \\
$\begin{array}{l}\text { Propane, } \mathrm{C}_{3} \mathrm{H}_{8} \\
\text { iso-Butane, }\end{array}$ & 0.02572 & 0.04185 & 0.04819 \\
$\mathrm{C}_{4} \mathrm{H}_{10}$ & 0.00553 & 0.01158 & 0.01332 \\
n-Butane, & 0.00843 & 0.01161 & 0.01332 \\
$\begin{array}{l}\mathrm{C}_{4} \mathrm{H}_{10} \\
\text { iso-Pentane, }\end{array}$ & 0.00265 & 0.00335 & 0.00405 \\
$\begin{array}{l}\mathrm{C}_{5} \mathrm{H}_{12} \\
\text { n-pentane, }\end{array}$ & 0.00195 & 0.00336 & 0.00405 \\
$\begin{array}{l}\mathrm{C}_{5} \mathrm{H}_{12} \\
\text { Hexane, } \\
\mathrm{C}_{6} \mathrm{H}_{14}\end{array}$ & 0.00174 & 0.00182 & 0.00224 \\
$\begin{array}{l}\text { Heptane }+, \\
\mathrm{C}_{7} \mathrm{H}_{16}\end{array}$ & 0.00178 & 0.00198 & 0.00233 \\
Carbondioxide, \\
CO
\end{tabular}

Table 3: Centrifugal Compressor Data sheet

\begin{tabular}{llll}
\hline Engine Parameter & $\begin{array}{l}\text { OEM } \\
\text { Data }\end{array}$ & $\begin{array}{l}\text { Simulated } \\
\text { Result }\end{array}$ & $\begin{array}{l}\text { Error } \\
\text { Margin } \\
(\%)\end{array}$ \\
\hline $\begin{array}{l}\text { Power Output }(\mathrm{kW}) \\
\text { Heat Rate(kJ/kWh) }\end{array}$ & $\begin{array}{l}10,660 \\
11,060\end{array}$ & 11,600 & 0.56 \\
$\begin{array}{l}\text { Efficiency } \\
\text { Exhaust }\end{array}$ & 32.5 & 32.4 & -0.58 \\
$\begin{array}{l}\text { Temperature(K) } \\
\text { Exhaust Flow }\end{array}$ & 761 & 766.9 & 0.31 \\
(kg/s) & 42.3 & 42.2 & -0.65 \\
Pressure Ratio & 13.8 & 13.8 & 0.23 \\
Turbine & 7,900 & 7,900 & 0 \\
Speed(rpm) & & & \\
\hline
\end{tabular}

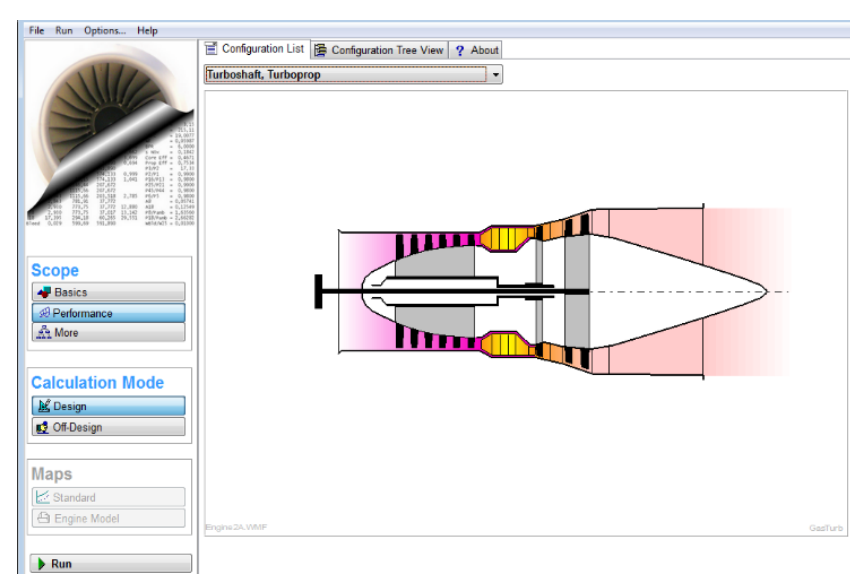

Figure 2: Twin shaft engine Configuration

This engine configuration was selected based on intended application, which is for driving a given centrifugal compressor in a pipeline station. The engine adopted and modeled in the simulation software was inspired from the PGT 16 class of GE gas turbines. Table 3 shows the design parameters obtained from open domain.

Based on the simulated centrifugal compressor performance results, the value of compressor power required for various composition of gas mix was used to match/ integrate the centrifugal compressor to its driver gas turbine. In addition, the recommended speed and compressor required power margins were also considered in the integration process, for optimum economic operations. Taher and MeherHomji [3] suggested a $2 \%$ for variation in speed and $14 \%$ for power consumption.

Consequent upon considering the outcome of performance analysis, the centrifugal compressor was matched/ integrated to the twin shaft gas turbine using the compressor required power and speed. Using the adopted approach, the three different gas mix compositions were analyzed.

With the obtained compressor power required from compressor performance, the performance of the gas turbine was simulated.

\section{RESULTS AND DISCUSSION}

\subsection{Centrifugal Compressor Performance Analysis}

As mentioned earlier, the performance of the centrifugal compressor is influenced by several factors. Amongst which are gas mix composition, inlet temperature and pressure etc.

According to Lapina [11] the performance of centrifugal compressor is affected by changes in atmospheric conditions such as relative humidity, barometric pressure etc. Though, the effect of relative humidity and barometric pressure is less significant on the centrifugal compressor when compared to inlet temperature. The changes in centrifugal compressor performance which are caused by fluctuating atmospheric conditions and other factors can be predicted by modifying the performance of the compressor.

Based on these findings, varying inlet temperature and gas mix compositions were investigated to ascertain their influence on the performance of the centrifugal compressor.

With the compressor data sheet, gas mix composition and compressor maps obtained, the Cmap software was employed to model and configure the machine. Table 4 shows the 
experimental and simulated machine performance parameters and the error margin between the experimental data and simulated values. The design point performance simulation results and experimental (original equipment manufacturers) data obtained were compared for validation. From the comparison of the simulated and original equipment manufacturer data, it is obvious that CMap software effectively predicted the design point performance data of the centrifugal compressor investigated. The error margin is relatively small, which signifies the level of accuracy of the simulated data.

Two separate investigations were conducted namely the influence of varying gas mix composition and inlet temperatures on the centrifugal compressor performance. In the case of varying gas mix composition, the centrifugal compressor was assumed to be operated at design inlet pressure and temperature. For varying inlet temperature, the investigations were carried out at design point inlet pressure while MANat gas was considered as adopted fuel.

To achieve the objective of this research, inlet temperatures varying from $20^{\circ} \mathrm{C}$ to $60^{\circ} \mathrm{C}$, in steps of $10^{\circ} \mathrm{C}$ were investigated. As can be seen from the plots, when inlet temperature was increased from $20^{\circ} \mathrm{C}$ to $60^{\circ} \mathrm{C}$ for a given rotational speed and gas mix composition (MANatGas), the compressor power required reduced (see Figures 3). This reduction in shaft horse power requirement can be attributed to a drop in mass flow rate caused by reduced volume flow density as a result of increased inlet temperature. These findings are in agreement with the results presented in Febo and Paganini [12]. Similarly, Figure 4 shows that the plots of polytropic head reduced with increased compressor inlet temperature.

In the case of gas mix compositions, gas compositions obtained from three different locations in the Niger Delta region were investigated. The gas mix compositions from the different locations were titled Lean Associated Natural Gas (LaNatGas), Mean Associated Natural Gas (MANatGas) and Rich Associated Natural Gas (RaNatGas) [10]. The Gas mix compositions are presented in Table 2 .

Figure 5 shows the plots of the influence gas mix on the centrifugal compressor required power. The figure shows that the highest power required by the compressor to transport a given volume flow of gas was observed in the RaNatGas mix when compared to the LaNatGas and MaNatgas mixtures. At a design inlet flow volume of 15928 cubic meters per hour, the compressor required power from the gas turbine drive to transport the RaNatGas is approximately $7450 \mathrm{~kW}$ as against $7065 \mathrm{~kW}$ and $6500 \mathrm{~kW}$ for MaNatGas and LaNatGas mixtures respectively.

Table 4: Centrifugal Compressor design point performance data

\begin{tabular}{lccc}
\hline Compressor Design Parameter & Experiment & Simulation & Error Margin (\%) \\
\hline Flow Volume, Q1 & $15928 \mathrm{~m}^{3} / \mathrm{h}$ & $15928 \mathrm{~m}^{3} / \mathrm{h}$ & 0 \\
Discharge Pressure , P2 & $31.8 \mathrm{bara}$ & $31.84 \mathrm{bara}$ & 0.13 \\
Discharge Temperature, T2 & 123 Celsius & 123.09 Celsius & 0.07 \\
Polytropic Head, HP & $143409.37 \mathrm{~J} / \mathrm{kg}$ & $143195.36 \mathrm{~J} / \mathrm{kg}$ & 0.15 \\
Polytropic Efficiency, ETAP & 0.834 & 0.834 & 0 \\
Power, Pw & $7065 \mathrm{~kW}$ & $7065 \mathrm{~kW}$ & 0 \\
\hline
\end{tabular}

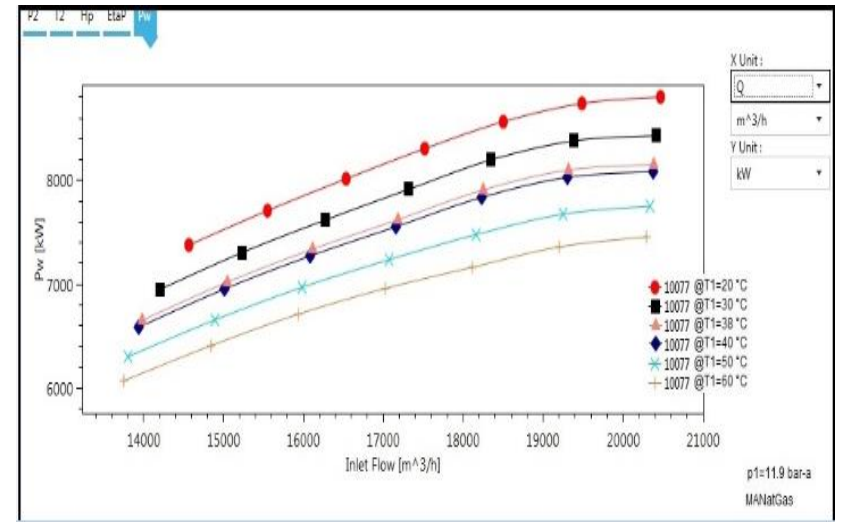

Fig 3: Plots of compressor power required against inlet flow volume at varying inlet temperature

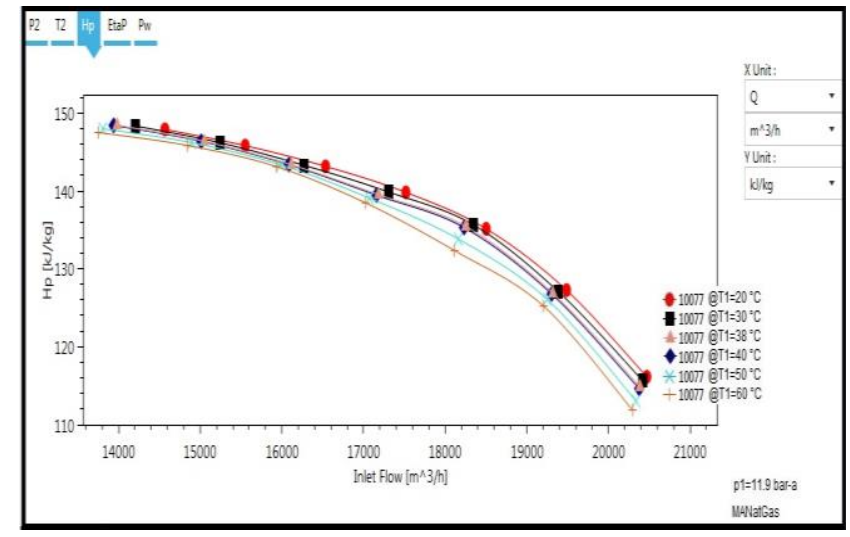

Fig 4: Plots of Polytropic Head against inlet flow volume at varying inlet temperature

Vol. 39, No. 4, October 2020 
These findings are in agreement with the results presented in Febo and Paganini [12] where gas mix of different molecular weights were compared.The plots of polytropic head, polytropic efficiency, discharge temperature and pressure against inlet flow volume are presented in the study to demonstrate the performance of the centrifugal compressor under different operating conditions. These parameters are presented in this study because according to Ramussen and Kurz [13], the performance of centrifugal compressors best presented using plots showing the isentropic efficiency and isentropic head as a function of the actual inlet flow. In addition, the authors stated that polytropic head and efficiency as a function of the actual inlet flow can be used as well to describe the performance of a centrifugal compressor

The plots of polytropic head and polytropic efficiency against inlet flow volume as shown in Figures 6 and 7 respectively follow similar trend to that of the compressor power plots where RaNatGas mix gives the highest in all the performance indices.

\subsection{Gas Turbine Performance Analysis}

Figure 8 shows the performance plots of the gas turbine integrated/ matched to drive a $2 \mathrm{BCL}$ centrifugal compressor. As can be seen in Figure 8, when the three gas mix compositions were compared, the compressor used in transporting RaNatGas requires the highest power from the gas turbine to drive the compressor than the other gas mix compositions. Similarly, the plots in Figure 9 indicates that the fuel flow to provide the required power from the gas turbine to drive the compressor for RaNatGas mixtures is highest when compared to MaNatGas and LaNatGas. The values of fuel flow for RaNatGas, MaNatGas and LaNatGas mixtures are $0.4971 \mathrm{~kg} / \mathrm{s}, 0.4780 \mathrm{~kg} / \mathrm{s}$ and $0.4507 \mathrm{~kg} / \mathrm{s}$ respectively. The outcome of the investigation of the influence of inlet temperature on the centrifugal compressor performance analysis conducted was also used to ascertain changes in the operational requirement from the gas turbine. Figure 10 indicates that with reduced inlet temperature in centrifugal compressor, the compressor will require more power to transport a given quantity of gas, which would translate to an increase in power turbine output as well as the speed to meet the new demand. Also, Figure 11 demonstrates that the fuel flow increased with reduced centrifugal compressor inlet temperature. This occurs as a result of the increased power

Nigerian Journal of Technology, demand from the centrifugal compressor. Hence, necessitating increased fuel flow so as to increase the power turbine power output, thereby causing the PT and the driven compressor to accelerate.

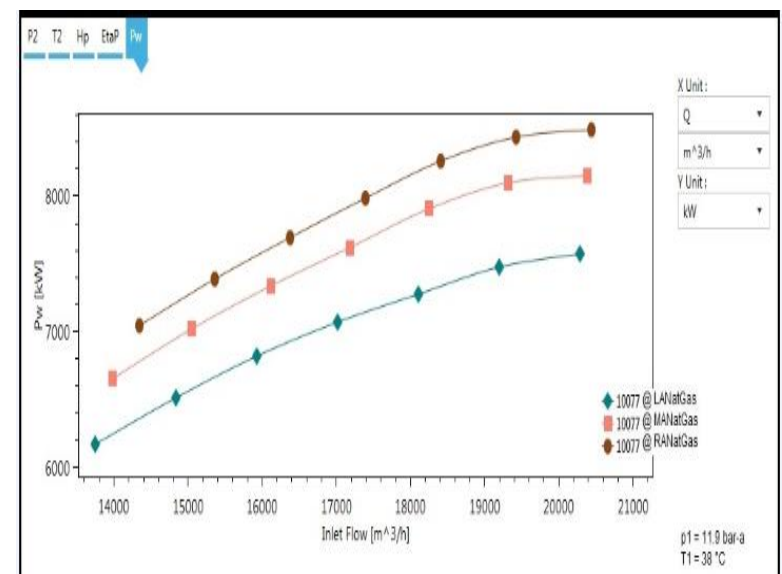

Fig 5: Plots of compressor power required against inlet flow volume

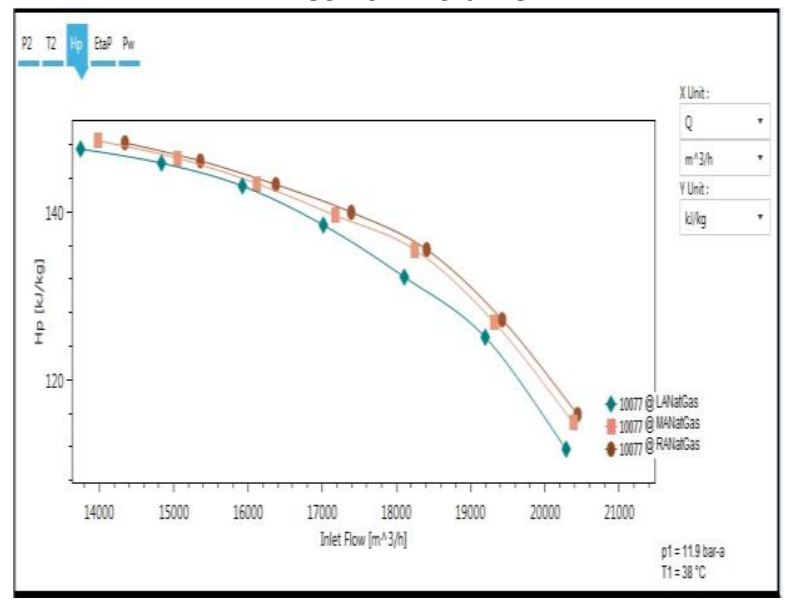

Fig 6: Plots of Polytropic Head against inlet flow volume

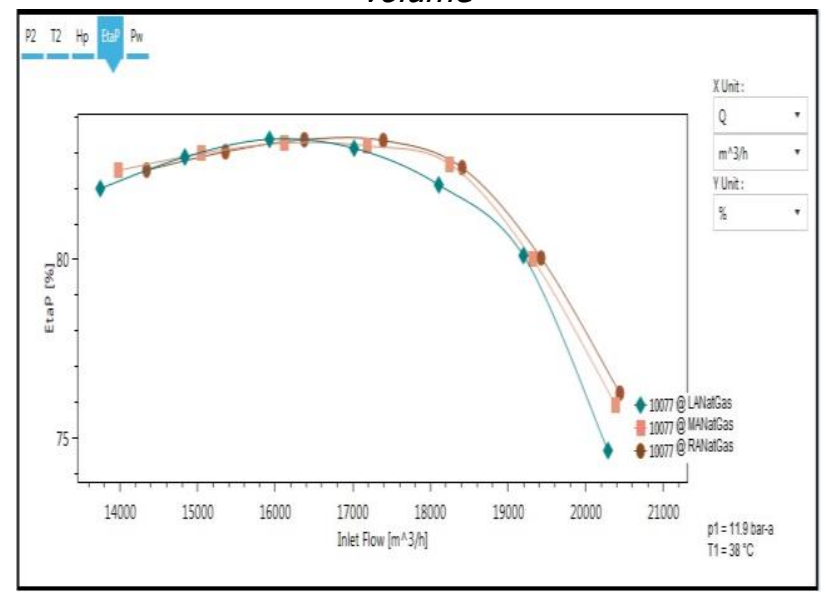

Fig 7: Plots of Polytropic Efficiency against inlet flow volume

\subsection{Techno-Economic Analysis}

Techno economic analysis was conducted to ascertain the cost benefits of using the gas turbine compressor set (combination of gas turbine and

Vol. 39, No. 4, October 2020 
centrifugal compressor), to transport the three different gas mix compositions to a given power plant located in the Niger Delta region. The analysis was done using heat rate, which is energy utilized (fuel consumption).

According to Boyce [14], the operating cost which is essentially the cost of energy accounts for about 70$80 \%$ of the life cycle cost of any power plant; while the remaining percentage is shared between the costs of a new power plant and maintenance costs. About $7-10 \%$ and $15-20 \%$ are the costs of a new power plant and maintenance costs respectively. This underscore the relevance of this study especially in today's world where prices of fuel are so high and environmental issues are of major concern.

It is assumed that the gas turbine under investigation operated 4000 hours per year. The operating hours of the gas turbine depends on the energy requirements from the national grid and the availability of fuel (gas). It is therefore presumed that the gas turbine operated for an average of 24hours daily, which translates to approximately over 8000hours for a year.

In conducting the techno economic analysis, the capital cost of gas turbine was not considered. Table 5 shows the parameters for the three different cases. The annual fuel cost [15] for the various cases was obtained using Equation (8).

$$
\begin{aligned}
& \text { Annual Fuel Cost } \\
& =\text { Engine Power Output } \times \text { Heat Rate } \\
& \times \text { Operating Hour per Year } \\
& \times \text { Fuel cost }
\end{aligned}
$$

Using equation (8), the annual fuel cost for the three cases was calculated and Table 5 shows the outcome of the calculations. Therefore, annual fuel cost for transporting LaNatGas, MaNatGas and RaNatGas fuels is presented in Table 6 .

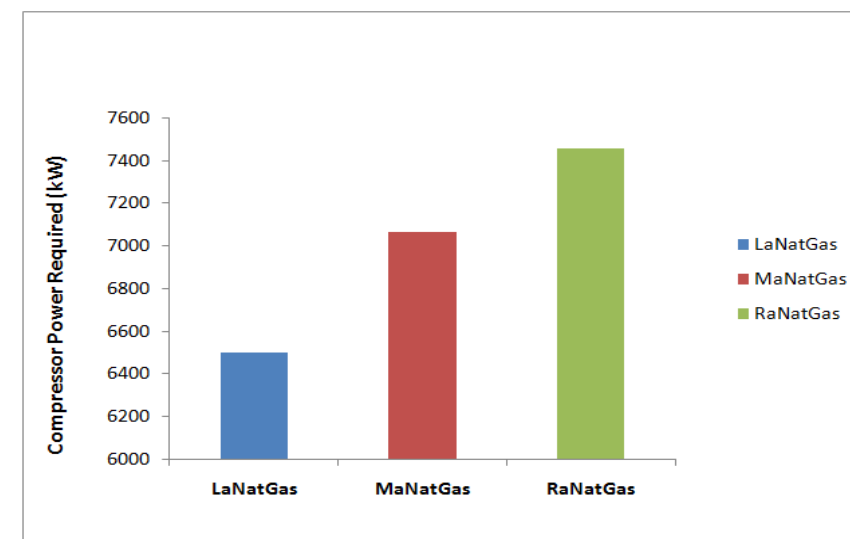

Fig 8: Plots of Compressor power required against varying gas mix

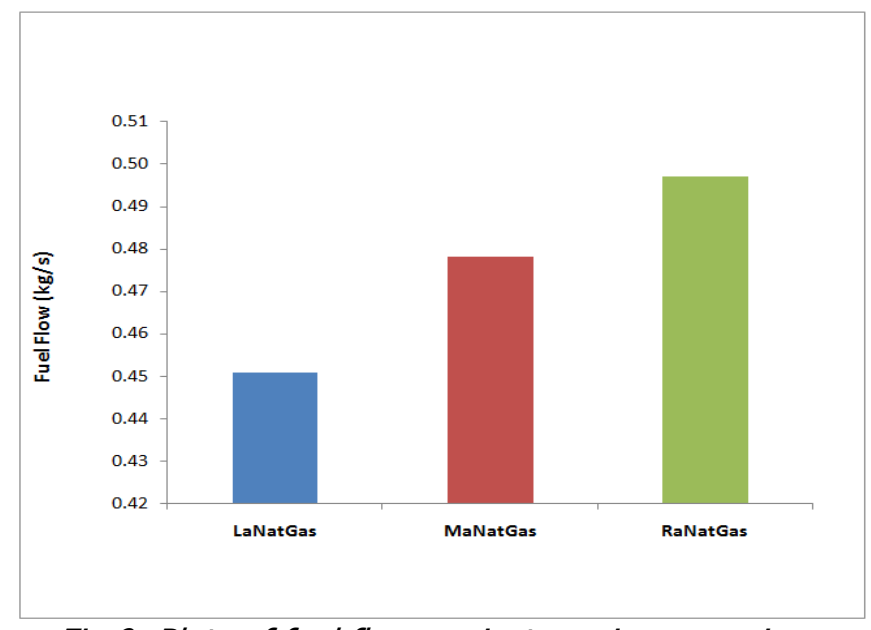

Fig 9: Plots of fuel flow against varying gas mix

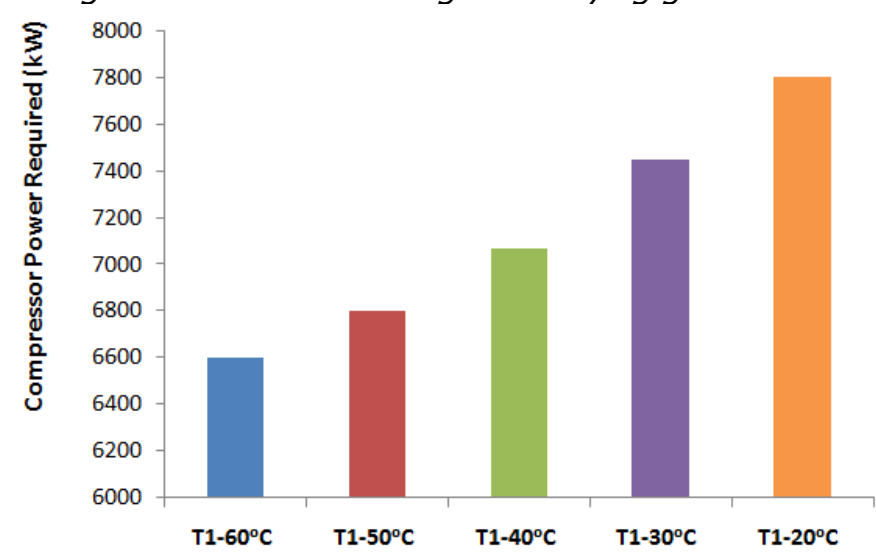

Fig 10: Plots of Compressor power required against

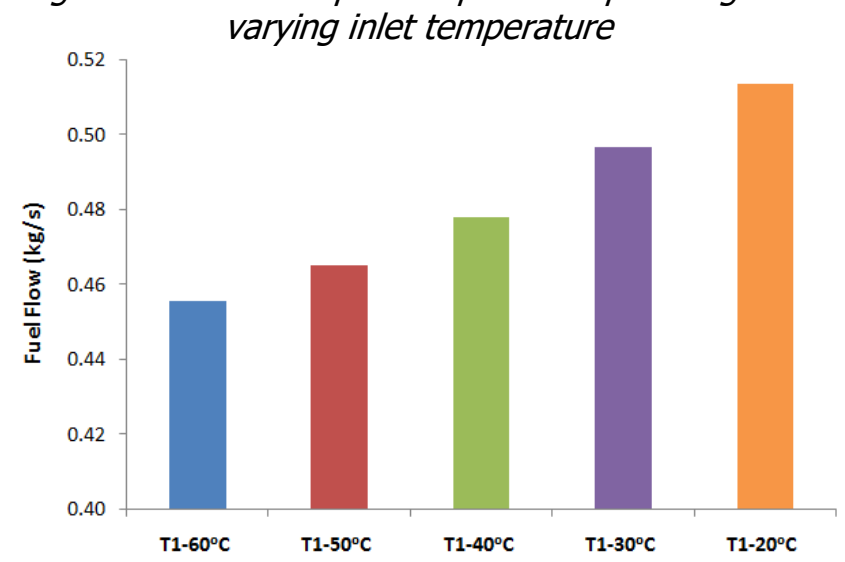

\begin{tabular}{|c|c|c|c|}
\hline Parameters & LaNatGas & MaNatGas & RaNatGas \\
\hline Power (kW) & & & 74 \\
\hline Heat Rate (kJ/kwh) & 12416.7 & 12116.5 & 11931.7 \\
\hline $\begin{array}{l}\text { Operating hours } \\
\text { per year (hrs) }\end{array}$ & 8000 & 8000 & 8000 \\
\hline $\begin{array}{l}\text { Cost Natural gas } \\
\text { (\$) }\end{array}$ & 20.17 & 20.17 & 20.17 \\
\hline
\end{tabular}

Fig 11: Plots of Fuel flow against varying inlet temperature

Table 5: Gas turbine Compressor Set operating data

Table 6: Annual Fuel cost for the various cases

\begin{tabular}{llll}
\hline Parameters & LaNatGas & MaNatGas & RaNatGas \\
\hline $\begin{array}{l}\text { Annual Fuel } \\
\text { Cost }(\$)\end{array}$ & $12,343,483$ & $13,092,084$ & $13,594,910$ \\
\hline
\end{tabular}




\section{CONCLUSION}

This work presents detailed analysis of integrating/ matching a given centrifugal compressor to a twin shaft aero-derivative gas turbine, for the purpose of transporting natural gas to a power plant located in Niger Delta. Gas mix compositions from three different locations in Niger Delta were obtained and labeled LaNatGas, MaNatGas and RaNatGas. With the compressor data sheet, gas mix composition and compressor maps obtained, the Cmap software was employed to model and configure the machine. Consequently, results obtained from the simulated centrifugal compressor were used to match/ integrate it to gas turbine driver

The influence of varying gas mix composition and compressor inlet temperature of the centrifugal compressor on the gas turbine performance compressor set was simulated.

At a design inlet flow volume of 15928 cubic meters per hour, the compressor required power from the gas turbine drive to transport the RaNatGas is approximately $7450 \mathrm{~kW}$ as against $7065 \mathrm{~kW}$ and $6500 \mathrm{~kW}$ for MaNatGas and LaNatGas mixtures respectively.

The techno-economic analysis of the gas turbine compressor set shows that the fuel cost of transporting a given volume flow of RaNatGas to specific location for a year gives about $\$ 13.5$ million when compared MaNatGas and LaNatGas mixtures which cost about $\$ 13.02$ million and 12.3 million respectively.

\section{REFERENCES}

[1] Al-busaidi, W. K. "Techno-economic Assessment of Radial Turbomachinery in Process Gas Applications", PhD thesis 2016, Cranfield University, Cranfield.

[2] Giacomelli, E., Bernardini, F. and Pini, A. "Application of Gas Turbine for Large Reciprocating Compressor Drive", Transaction of the ASME 89- GT-154, 1989.

[3] Taher, M. and Meher-Homji, C. "Matching of gas turbines and centrifugal compressor in oil and gas industry", Proceeding of ASME Turbo Expo, 11-15 June, 2012, Copenhagen, Denmark

[4] Meher-Homji, C. B., Mathews, T. and Weyermnn, H. P. "Gas Turbine and Turbocompressors for LNG services", 36th Turbomachinery Symposium, 2007.
[5] Kurz, R., Brun, K. and Thorp, J. "Process control with industrial gas turbines - Tutorial," 46th Turbomachinery and 33rd Pump Symposia, Houston Texas, 11-14 September, 2017.

[6] Overli, J. M. "Turbine or Electrical Motor driven gas compressors on production platforms", Transaction of the ASME 83- GT-114, 1983.

[7] Kurz, R. and Sheya, C. "Gas Turbines or Electric Drives in Offshore Applications," ASME Paper GT2005-68003, 2005.

[8] Shah, P., Wealtherwax, M., Chpeux, M., Masani, K. and Merher-Homji C. B. "Refrigeration Compressor Driver Selection and Technology Qualification", 1 th International Conference and exhibition on Liquiefied Natural Gas, 2013, Paper number 2-5, LNG17.

[9]Rofiq, Z. A. "Review of wet gas compressor performance", MSC Thesis 2014, Norwegian University of Science and Technology, NTNUTrondhein

[10] Allison, I. "Techno-economic evaluation of associated gas usage for gas turbine power generation in the presence of degradation and resource decline"PhD thesis, 2014, Cranfielduniversity, Cranfield.

[11] Onoroh, F., Ogbonnaya, M. and Onochie, U. P. "Modeling and Simulations of the Effect of Moisture Content and Ambient Temperature on the Gas Turbine Power Plant Performance in Ughelli, Nigeria", Nigerian Journal of Technology Vol. 39, No.1, 2020 pp. 182-188.

[12] Lapina, R. P. "Estimating Centrifugal Compressor Performance", Vol. 1, Houston: Gulf Publishing, 1982.

[13] Febo, M.D. and Paganini, P. "Compressor map modification in off design conditions", Tech Brief 2018 Edition

[14] Rasmussen, P. C. and Kurz, R. "Centrifugal Compressor applications-upstream and midstream", 38th Turbomachinery Symposium, 2009.

[15] Boyce, M. P. "Performance characteristics of advanced gas turbine cogeneration power plants", American Society of Mechanical Engineers, Manufacturing Engineering Division, MED, Vol. 16-2, 2005, pp. 1369.

[16] Ganapathy, V. "Steam Plant Calculations Manual", 2nd ed, 1999, CRC press. 